\title{
AGENT-BASED CONTRACTING IN VIRTUAL ENTERPRISES
}

\author{
Claudia Cevenini, Giuseppe Contissa, Migle Laukyte \\ CIRSFID, University of Bologna, Palazzo Dal Monte Gaudenzi, \\ via Galliera, 3,Bologna, I-40121, ITALY \\ Tel: +39051 277237, Fax: +39051 260782, Email: \{cevenini, contissa, \\ mlaukyte\}@cirsfid.unibo.it
}

\begin{abstract}
Virtual Enterprises (VEs) use software agents (SAs) to reduce costs, speed up operations, and increase efficiency and competitiveness. Agents can carry out negotiations and make contracts without any human intervention. This makes them useful both in negotiations to set up a VE and in contracting with VE partners. Agents raise legal problems about the relevance and validity of their actions. The law may not always offer a solution to agent-based interactions. This paper investigates whether current laws are suitable to regulating agents and what new rules mav need to be introduced.
\end{abstract}

This paper is partly based on research conducted for the EC project LEGALIST (IST-2-004252-SSA, FP6 IST Programme).

\section{INTRODUCTION}

The use of Software Agents (SAs)-generally in electronic commerce, and particularly by Virtual Enterprises (VEs) - comes with both numerous business benefits and problems to solve. The autonomy of SAs obstructs their application, because this autonomy may result as unpredictability and the actions of SAs may lack legal relevance and may be invalid. The normative framework addresses some of these issues but not all.

Therefore, we point out the questions that remain unsolved by the legal framework. On the one hand, the aim is to integrate the SA's activities within the relevant regulations and, on the other hand, if these regulations hinder agents' utilization and generally cramp the technological development, propose the new ones.

The remainder of the paper is organized as follows. In Section 2 we discuss the basic notions of this paper: VEs and SAs, focusing on how VEs apply SAs. One of the most useful applications is to employ the agents in contractual activities both in negotiation stage during VE's formation, and operation stage of contracting with parties inside and outside the VE. In Section 3 we examine the present legal framework and we question its adequacy to regulate SAs. So in Section 4 we

Cevenini, C., Contissa, G., Laukyte, M., 2007, in IFIP International Federation for Information Processing, Volume 243, Establishing the Foundation of Collaborative Networks; eds. Camarinha-Matos, L., Afsarmancsh, H., Novais, P., Analide, C.; (Boston: Springer), pp. 225-232. 
investigate the possibility to introduce new rules which could fill in the gaps in normative framework substituting or integrating the existing regulations on regard. Section 5 concludes the paper with recommendations on possible directions for further research.

\section{VIRTUAL ENTERPRISES (VES) AND SOFTWARE AGENTS (SAS): DEFINITIONS AND APPLICATIONS}

For the scopes of the paper, we define VE on two perspectives: business and legal one. In a business perspective, VE is a collaboration of legally independent subjects, set up to rapidly and effectively exploit business opportunities and jointly bring products and services to the market. In a legal perspective, VE is a temporary, often cross-border ICT-enabled collaboration (without a separate legal status) between legally independent entities aimed at the joint provision of goods or services, where each partner contributes to particular task and activities.

For our purposes, we will use the definition of (Hayes-Roth, 1995): SA is a computational entity that able to interact with the environment in which it operates, through the performance of three basic capabilities: to perceive its environment, to proceed the information coming from the environment and to perform of actions aimed at modifying its status.

This set of SAs' capabilities explain why VEs use them: these capabilities enable SAs to substantially contribute to reduce costs, to speed up business operations, to increase efficiency and so competitiveness.

In particular, the SAs are applicable in all the spectrum of contractual activities from negotiations to set up the VE, to final contracting with other parties both inside and outside the VE during its operational phase.

The negotiations phase before the setting up of a VE project includes agents which compare the different business structures regulated by national legislation and set up an organization. They match or avoid matching one or more of business structures on the basis of the needs of the initiative. Afterwards, SAs will perform pre-contractual activities on behalf of the partners. Agents have to act in good faith and in a law-abiding manner (Brazier, 2002). Thus the negotiations conducted by agents can become gentlemen's agreements and pre-contractual arrangements with potential partners. (Matskin, 2001) present and (Petersen, 2003) propose to apply AGORA multi-agent architecture which is the example of VE formation using SAs.

Prototype PROVE $^{1}$ is another example of SAs used to form VE, where agents conduct the negotiations according to the rules coded in them (Szirbik, 2000). Thus the VE partners have to personalize SAs by introducing the rules they want SAs to use during the negotiations or at least review the rules SAs already have.

During VE's operation stage, VE partners may use the agents in all stages of the value chain and in managing both internal and external interactions. The drafting of general VE interchange agreement, which regulates the overall management of the

${ }^{1}$ Prototype PROVE makes part of research project ROVE (Reasoning about Operations in Virtual Enterprises) at Eindhoven University of Technology (The Netherlands). 
VE (comprising the use of SAs) and the activities of its partners, is made by VE partners themselves. Instead agents could offer substantial support in the execution of minor contracts, especially if the latter are standardized. In fact (Radin, 2000) affirms that contracts stipulated by SAs are the ones which only offer a contract on the user's behalf when an opportunity arises: the agent is only offering to trade the contract, stopping short of executing it on its own.

This vast applicability has to consider the legal framework, which regulates the contractual activities, involving the SAs. The following Section 3 addresses the points of intersection between normative regulation and agent's actions in VE.

\section{LEGAL FRAMEWORK: STATE-OF-ART}

VE partners implementing agent technologies must achieve the compliance of SA's actions with the applicable legal framework. Besides, agents move through open networks which are international by nature, and thus can perform actions which are deemed perfectly legal by some systems and illicit by other ones. In fact, global performance of on line contracts can be problematic. The legislations on contracting and on the use of technical tools van actually be extremely different and contrast with the basic principles that are applied in the legal environment of European Union.

The contract counterpart can be imposed with specific acknowledgements, such as accepting the use of SAs in negotiating and concluding of the contract, and also limiting the liability of the agents' user(s): example of such limitation is the rule which permits to close a contract only to subjects who are resident - or which have their main seat in case of companies - in certain countries or main geographical areas.

In the negotiation and contracting stages, agents are assigned tasks and goals according to which they contact potential contracting parties, negotiate with them and conclude contracts on behalf of the VEs' partners. In performing all these tasks, it is vital that SAs do not infringe other subjects' rights, such as copyright or the right to privacy and that they do not enter protected computer systems without the administrator's authorization.

Article 12(14) of ) of "Legal Aspects of Electronic Commerce, Electronic Contracting: Provisions for a Draft Convention," of The United Nations Commission on International Trade Law (UNCITRAL) takes up the question of the "use of automated information systems for contract formation," setting forth the so-called non-discrimination rule, whereby a contract closed by SAs - either fully (both parties to the contract are SAs) or in part (only one of the parties is SA) - "shall not be denied validity or enforceability on the sole ground that no person reviewed each of the individual actions carried out by such systems or [reviewed] the resulting agreement." 2 In other words, these kinds of contracts will be valid even without the

${ }^{2}$ Art. 12(14) of "Legal Aspects of Electronic Commerce, Electronic Contracting: Provisions for a Draft Convention," UNCITRAL (2004) A/CN.9/WG.IV/WP. 108, online at http://daccessdds. un.org/doc/UNDOC/LTD/V04/541/06/PDF/V0454106.pdf?OpenElement. 
user's acceptance of their terms and conditions. On the one hand, such recognition marks a big step towards legal acknowledgement of SAs as participants in e-commerce; but on the other hand, is SA technology so developed as to ensure there will be little or no risk of the user being held answerable for errors made by the SA? These errors have sometimes been big blunders, and the likelihood of this happening on more than a few rare occasions may discourage the e-community from using agents.

Surely, today we cannot say that nothing can go wrong in the process of contractmaking through the use of SAs. There are many consequential errors an SA may make: The SA could sell an item for an incorrect price or pay an incorrect amount for it, or the SA may purchase an incorrect amount of items, or it may make a purchase on conditions harmful to its user. Article 14(16) of UNCITRAL addresses the question of errors, but only human error: "if a person made an error" (italics added). So there is no legal remedy that the document sets out for errors on the SA's part. The Working Group ${ }^{3}$ recognized the complexity in working out legal devices to handle such errors, but haven't yet decided on how to proceed. Thus the question remains open.

The Uniform Computer Information Transactions Act (UCITA, 2002) leaves it to the courts to decide whether an electronic mistake, fraud, or the like, will contribute to a finding that no contract has been concluded.

This UCITA initiative has been widely challenged for enhancing deployment of "poorly understood, and potentially fallible technologies, such as [...] electronic agents" (Fromkin, 1998), thus weakening consumer protection. This is one of the main problems to be solved.

The question of electronic contracts is addressed in the EU Directive on Electronic Commerce (Directive 2000/31/EC), ${ }^{4}$ but without specifying the means used for such contracts. Nevertheless, this directive does stress the legal "weight" these contracts carry, and so sets out a duty to remove any obstacles barring their use.

This article, in other words, upholds the legal validity of electronic contracts and encourages the lawmaking bodies of every Member State to write provisions introducing electronic contracts into its national laws on contracts and making their use a legitimate, standard practice.

Article 10 of the same directive requires clearly illustrating to consumers the entire process of contract formation. This requirement contributes to the use of SAs in contract-making, because it makes it mandatory to specify the functioning of SAs.

\footnotetext{
${ }^{3}$ The Working Group took as its model the Uniform Electronic Commerce Act of Canada (1999), which deals specifically with errors made by electronic agents in electronic documents, http://www.ulcc.ca/en/us/index.cfm?sec=1\&sub=lul,

${ }^{4}$ Directive 2000/31/EC of the European Parliament and of the Council of 8 June 2000, on certain legal aspects of information-society services, with particular reference to electronic commerce in the Internal Market (Directive on Electronic Commerce), online at http://eur-lex. europa.eu/LexUriServ/LexUriServ.do?uri=CELEX:32000L0031:EN:NOT.
} 
Failure to clearly explain these matters is one of the main obstacles to building consumer confidence in this technology. Such an explanation of an SA's functioning should not be underestimated: The clearer (and more user-friendly) an SA will be to consumers, more will consumers be inclined trust and use it. The programmers' community should more actively interact with consumer associations, working together to draft a step-by-step explanation of how SAs function, of what they can and cannot do, etc.

Clearly, SAs are very often perceived today as "unknown animals," and the layperson is skeptical about using them, so this requirement to explain the contractformation process should help SA technology come into wider use in transacting business between consumers and merchants in e-commerce.

If the VE contract counterpart is a consumer, VE partners should bear in mind the rules on consumer protection, in particular those set by Directive 97/7/EC on distance contracts and its amendments introduced in Directive 2002/65/EC on distance marketing of consumer financial services. Furthermore, VE partners should also consider vexatious clauses (for those the reference should be maid to Directive $93 / 13 / \mathrm{EC}$ on unfair terms in consumer contracts). The VE shall, in particular, comply with the duties of information and the right to return the purchased goods. If SAs execute on line contracts, they must be able to provide said information and to enable consumers to exercise their rights. In this context, it is necessary to inform users that they are in fact interacting with a technical device and not with a human counterpart. Additional information may concern technical indications on the functioning of the agent and on the legal framework applicable to contract.

\section{NEW RULES: PROPOSALS FOR FILLING IN THE GAPS OF LEGAL FRAMEWORK}

We cannot say how will develop SAs in the future, and that is perhaps what is holding back the effort to bring their use under a specific regulatory framework. If the governments will introduce the legislation on SAs, after a while these governments will have to update, rewrite and supplement this legislation.

We already mentioned Directive on Electronic Commerce (Directive 2000/31/EC) as the main law to regulate contractual activities of SAs. This directive makes no specific reference to SAs, but it does not rule out their use in e-commerce, either. Therefore, if this Directive legitimates contracts formed by electronic means, there is no need for a specific legislation: existing law suffices to ensure legal certainty. If new issues will emerge, existing norms could resolve them and there is no need to introduce new legislation.

Thus the main undertaking should be not to introduce new rules on SAs, but to clarify the law already in force, this by putting out recommendations and guidelines, especially on the following points:

(a) offering a clear definition of SA, because the term agent itself generates ambiguity with regard to the law of agency. Furthermore, the definitions available today (UCITA, UNCITRAL) fail to reflect the relevant characteristics of SAs, such as autonomy and mobility. We suggest defining a SA a computer program capable of flexible and autonomous action in a dynamic environment, typically an environment in which multiple agents interact; 
(b) we should spell out-for users (in this case, VE partners) and developers alike - the risks they face in case a SA malfunctions or oversteps the powers entrusted to it. The main issue is liability, the real sticking point, and if it cannot be clarified, then maybe we do need legislation to cover this specific area. Naturally, if an agent user is liable for the agent's actions, the user will have to be fully informed about what the SA can do. Such information is as yet unavailable.

(c) the parties to SAs-based contracts should have as much latitude as possible in agreeing to terms and conditions, without much interfering legislation going into the details of what can and cannot be done;

(e) at the same time, it would be useful - at least in the early stages - if we had a uniform contractual framework setting out basic rights for the parties engaged in SAs contracting. The best way to solve this problem might be to set up some form of collaboration among all the parties involved (programmers, business, consumers, lawyers) in drafting model contracts: unfortunately, no such initiative that we know of has so far been launched.

The regulation of agents can prove problematic in a non-hierarchical, dynamic organizational structure such as the VE. So the agreements drafted between VE partners can play an important role and be a first step toward the drafting of model contracts that will clearly illustrate the functioning of SAs. These agreements may be a part of a VE interchange agreement. The LEGAL-IST project has created a template for a license agreement for use of software agents, and this template could serve as an example. A special section of the agreement about SAs can be envisaged, in relation to the complexity of these tools and the absence of a specific legal framework. The VE partners not only specify the agents they will use (in other words, VE partners have to agree to use specialized software which permits mobile agents to run on computer system ${ }^{5}$ of VE partners), but also identify the trusted third party (Software Agent Common Provider (SACP) to install this software and to take further care of upgrading and testing it (Szirbik, 2000). Furthermore, this agreement can define the actions that an agent shall be allowed to take and set limitations to this purpose. In contracting, these limits can be set on the type of contract or on its monetary value, or, again, on the type of subjects with which the agent is allowed to negotiate and perform contract activities, for example in relation to their nationality.

It may be expected, too, that agents should use digital signatures to strengthen the evidentiary value of contracts and to make for greater confidence, since the digital signature can identify the person who liable for an SA's actions. If so, the interchange agreement should have detailed provisions on the use of digital signatures by SAs. These can concern, inter alia, the technical specifications that the signature should comply with, with particular reference to purposes of compatibility; reference can be made to internationally recognized standards ${ }^{6}$, as the European Directive on electronic signatures (Directive 1999/93/EC) abstains from imposing any specification on compatibility. The signature certificate can include agreed

\footnotetext{
${ }^{5}$ Also called Mobile Agent Server or simply dock.

${ }^{6}$ For example, the ones released by International Standard Organisation (ISO), International Electrotechnical Commission (IEC) and International Telecommunication Union (ITU).
} 
limitations on the use of signatures: it is possible to differentiate these limitations as these may depend on specific factors.

Other problems to be addressed in this case is that of different legal requirements different countries have for digital-signature certificates. In Europe the issue is covered under Directive 1999/93/EC, but the problem still remains with regard to the law of non-EU countries.

\section{CONCLUSIONS}

In this paper initially we have presented the basic notions of discussion: VE and SA, focusing our (and your) attention on the use of SAs by VE in contractual activities, which include both negotiations to contract and contracting itself. We have glanced over the current legal framework and investigated its relevance to regulate these contracts. The legislation applicable to SAs becomes numerous when the contracts closed by SAs involve not only VE partners, but also the consumers. After we have individuated the gaps of SAs' legal regulation and proposed the improvements that should be made to facilitate SAs-based contracting in electronic commerce.

Further steps to be made are to contribute to open standards creation process. VEs are end-users of SAs technologies, which put in practical campus these applications. So their experience can be of great value when identifying the problems and the issues to have in mind while drafting the standards.

The development of standardized contracts for SAs could be the second positive initiative of collaboration between computer science, business and legal fields. Standardized contracts could include several types of contracts: model contract between SA and consumer, model contract between VE partners for application of SAs, model contract between VE partners and trusted third party (SACP) with particular emphasis on role assignment between the parties.

\section{REFERENCES}

1. 1. Hayes-Roth H. An Architecture for Adaptive Intelligent Systems, in Artificial Intelligence: Special Issue on Agents and Interactivity, 72, 1995, pp. 329-365

2. 2. Brazicr F., Kubbc O., Oskamp A., Wijngaards N. Are Law Abiding Agents Realistic?, in Procecdings of the LEA02 Workshop, Bologna, 2002

3. 3. Radin M.J. Humans, Computers and Binding Commitment, in Indiana Law Journal, 2000, http://cybcr.law.harvard.cdu/ilaw/Contract/Radin_Full.html.

4. 4. Matskin M., Kirkeluten O.J., Krossnes S.B., Sælc Ø. AGORA: An Infrastructure for Cooperative Work Support in Multi-Agent Systems, in Wagner T., Rana O. (cds) Infrastructure for Agents, MultiAgent Systems, and Scalable Multi-Agent Systems. Springer-Verlag, LNCS, Volume 1887, 2001, pp. 28-40, http://www.springerlink.com/content/hqnm6dktghy35vxf/fulltext.pdf.

5. 5. Petersen S.A., Rao J., Matskin M. Virtual Enterprise Formation with Agents - An Approach to Implementation, in IEEE/WIC International Conference on Intelligent Agent Technology, (IAT), 1316 October 2003, pp. 527-530, http://iccexplorc.icce.org/icl5/8789/27820/01241137.pdf.

6. 6. Szirbik N., Acrts A., Wortmann H., Hammer D., Goossenaerts J. Mediating Negotiations in a Virtual Enterprise Via Mobile Agents, in Procecdings of Academia/Industry Working Conference on Rescarch Challenges 2000, 27-29 April, 2000, pp. 237-242, http://iccexplore.icc.org/icl5/6809/18271/00843300. pdf.

7. 7. Fromkin A.M. Article 2B as Legal Software for Electronic Contracting - Operating System or Trojan Horse?, http://papers.ssm.com/sol3/papers.cfm?abstract_id=146908

8. 8. Directive 2000/31/EC on clectronic commerce, http://curopa.cu.int/cur-lex/pri/cn/oj/dat/2000/1 178/ 1_17820000717en00010016.pdf 
9. 9. "Legal Aspects of Electronic Commerce, Electronic Contracting: Provisions for a Draft Convention”, UNCITRAL(2004) A/CN.9/WG.IV/WP.108, available at http://daccessdds.un.org/doc/ UNDOC/LTD/V04/541/06/PDF/V0454106.pdf?OpenElement;

10. 10. UCITA (Uniform Computer Information Transactions Act, 2002), http://www.law.upenn.edu/ bll/archives/ulc/ucita/2002final.htm 